University of South Carolina

Scholar Commons

1996

\title{
The Effects of Multiple Electroplated Zinc Layers on the Inhibition of Hydrogen Permeation Through an Iron Membrane
}

\author{
D. H. Coleman \\ University of South Carolina - Columbia \\ G. Zheng \\ University of South Carolina - Columbia \\ Branko N. Popov \\ University of South Carolina - Columbia, popov@engr.sc.edu \\ Ralph E. White \\ University of South Carolina - Columbia, white@cec.sc.edu
}

Follow this and additional works at: https://scholarcommons.sc.edu/eche_facpub

Part of the Chemical Engineering Commons

\section{Publication Info \\ Journal of the Electrochemical Society, 1996, pages 1871-1874.}

(c) The Electrochemical Society, Inc. 1996. All rights reserved. Except as provided under U.S. copyright law, this work may not be reproduced, resold, distributed, or modified without the express permission of The Electrochemical Society (ECS). The archival version of this work was published in the Journal of the Electrochemical Society.

http://www.electrochem.org/

Publisher's link: http://dx.doi.org/10.1149/1.1836917

DOI: $10.1149 / 1.1836917$

This Article is brought to you by the Chemical Engineering, Department of at Scholar Commons. It has been accepted for inclusion in Faculty Publications by an authorized administrator of Scholar Commons. For more information, please contact digres@mailbox.sc.edu. 


\title{
The Effects of Multiple Electroplated Zinc Layers on the Inhibition of Hydrogen Permeation Through an Iron Membrane
}

\author{
D. H. Coleman, ${ }^{*}$ G. Zheng, ${ }^{*}$ B. N. Popov, ${ }^{* *}$ and R. E. White** \\ Department of Chemical Engineering, University of South Carolina, Columbia, South Carolina 29208, USA
}

\begin{abstract}
The Devanathan-Stachurski permeation technique ${ }^{1-3}$ was used to investigate the rate of hydrogen permeation through an iron membrane with consecutively electroplated zinc layers. Hydrogen evolution rates and hydrogen permeation rates were followed as functions of time at different applied potentials. Hydrogen evolution and permeation decreased with each successive zinc layer until finally reaching an average decrease of 93 and $96 \%$, respectively, as compared with bare iron. Hydrogen surface coverage, exchange current density, absorption-adsorption reaction constant, and hydrogen recombination constant were estimated on bare iron and on zinc-plated iron. It was found that the decrease in the permeation rate of hydrogen through the iron membrane was due to (i) the decrease of hydrogen discharge rate and (ii) the suppression of hydrogen absorption and adsorption on the deposited zinc layers.
\end{abstract}

\section{Introduction}

Hydrogen can cause embrittlement of metals and alloys during electroplating, cathodic protection, and corrosion of metals. ${ }^{4-7}$ Surface modification has been used to reduce hydrogen-induced failures. ${ }^{8-17}$ Chen and $\mathrm{Wu}^{8,9}$ reported that electroplating of copper, tin, and silver reduce hydrogen evolution (HE) of type AISI 4140 steels. A permeation inhibition efficiency up to $93 \%$ was observed for copperplated steel. Zamanzadeh et $a l^{10}$ found that deposits of $\mathrm{Sn}$ and $\mathrm{Cd}$ decrease the hydrogen absorption on iron. The mechanism for reducing the hydrogen permeation rate and consequently the HE was due to the barrier effect of tested coatings which have lower hydrogen diffusion coefficients compared with the substrates. For example, the hydrogen diffusion coefficient of $\mathrm{Sn}$ and $\mathrm{Cd}$ are in the order of $10^{-10} \mathrm{~cm}^{2} / \mathrm{s}$ which is five orders of magnitude lower than that of iron.

Another approach for decreasing the hydrogen permeation by surface modification is to inhibit the hydrogen discharge reaction or to reduce the hydrogen absorption rate so that most of the hydrogen atoms adsorbed on the surface will form hydrogen molecules rather than be adsorbed and diffuse into the bulk of the substrate. ${ }^{11-17}$ According to our earlier studies, ${ }^{12,13}$ polarization and permeation experiments showed that lead and bismuth deposited layers inhibited the evolution and penetration of hydrogen through AISI 4340 steel alloy and Inconel 718 alloy. We also found that the hydrogen permeation is also inhibited in the presence of underpotentially deposited zinc (UPD). ${ }^{17}$ The observed effects were due to the kinetic limitations of the hydrogen discharge reaction and suppression of the hydrogen absorption by the deposited monolayers.

The objective of this study was to investigate the effect of bulk deposition of the zinc layer on the hydrogen permeation through an iron membrane. An attempt was also made to determine the dependence of the hydrogen permeation on the thickness of deposited zinc layers.

\section{Experimental}

The permeation experiments were carried out in a twocompartment system separated with a bipolar iron membrane. ${ }^{1-3}$ The hydrogen evolution current and hydrogen permeation current were measured continuously as functions of time. On the anodic side of the membrane, the potential was held constant at $-0.30 \mathrm{~V} v s$. a $\mathrm{Hg} / \mathrm{HgO}$ reference electrode. This potential corresponds to a practically zero concentration of absorbed atomic hydrogen on the surface. ${ }^{1}$ An iron membrane with thickness $L=0.1 \mathrm{~mm}$

* Electrochemical Society Student Member

** Electrochemical Society Active Member. was used. Prior to the experiment the membrane was prepared by polishing with $0.5 \mu \mathrm{m}$ high purity alumina powder and cleaning in an ultrasonic cleaning bath. Just prior to placing the membrane in the permeation cell, it was etched for $20 \mathrm{~s}$ in a methyl alcohol solution containing $1 \%$ $\mathrm{H}_{2} \mathrm{SO}_{4}$, then rinsed with deionized water, and dried in air.

To avoid oxidation of the iron membrane surface on the anodic side a thin layer of palladium was electroplated on this surface. The electrodeposition of palladium was carried out using $2 \mathrm{mg}$ of $\mathrm{Na}_{2} \mathrm{Pd}\left(\mathrm{NO}_{2}\right)_{4}$ in $0.2 \mathrm{M} \mathrm{NaOH}$ at a current density of $200 \mu \mathrm{A} / \mathrm{cm}^{2}$ for $4 \mathrm{~h}$ with the membrane in the permeation cell. The anodic compartment was then drained, rinsed with deionized water, and refilled with fresh $0.2 \mathrm{M} \mathrm{NaOH}$. Both the anodic and cathodic solutions were pre-electrolyzed for $24 \mathrm{~h}$ in separate electrolytic cells prior to the experiments to remove any impurities in the solutions. After plating the palladium on the anodic side, the cathodic side was filled with an electrolyte containing $1.0 \mathrm{M} \mathrm{H}_{3} \mathrm{BO}_{3}, 1.0 \mathrm{M} \mathrm{Na}_{2} \mathrm{SO}_{4}$, and $0.4 \mathrm{M} \mathrm{NaCl}$. The membrane was then saturated with hydrogen to fill possible irreversible trapping sites in the membrane by keeping the cathodic side applied potential at $-0.80 \mathrm{~V}$ vs. SCE until the measured permeation current was constant. Nitrogen gas was bubbled through both compartments during the experiments to remove any dissolved oxygen.

The zinc layers were deposited using a solution with the same constituents as the cathodic solution (i.e., 1.0 M $\mathrm{H}_{3} \mathrm{BO}_{3}, 1.0 M \mathrm{Na}_{2} \mathrm{SO}_{4}$, and $0.4 M \mathrm{NaCl}$ ) with the addition of $0.05 \mathrm{M} \mathrm{ZnSO}_{4}$. Each layer was deposited galvanostatically at $1 \mathrm{~mA}$ for 10,20 , or $40 \mathrm{~s}$. Assuming $100 \%$ current efficiency, this would correspond to an approximately $0.03 \mu \mathrm{m}$ thick layer for each $40 \mathrm{~s}$ of plating. Plating times shown in the experimental results are cumulative plating times. Measurements of the cathodic current and permeation current at different applied cathodic potentials, $E_{\mathrm{c}}$, were made on the bare iron substrate and subsequently after each zinc layer was plated.

\section{Results and Discussion}

The experimental data obtained in these experiments was analyzed using the Iyer, Pickering, and Zamanzadeh (IPZ) model ${ }^{18,19}$ to calculate kinetic parameters for the exchange current density, the hydrogen absorptionadsorption constant, the hydrogen surface coverage, the transfer coefficient, and the recombination rate constant. This model assumes that the hydrogen reaction occurs via the coupled discharge-recombination mechanism. Additional assumptions are that (i) the hydrogen atom oxidation can be neglected $(\eta \gg R T / F)$; (ii) the Langmuir isotherm is used to describe the hydrogen coverage of the substrate surface; (iii) the intermediate hydrogen absorption-adsorption reaction is in local equilibrium; 
and (iv) the hydrogen permeation process is described by a simple diffusion model through the membrane. From these assumptions the following equations can be derived ${ }^{18,19}$

$$
\begin{gathered}
i_{\mathrm{c}}=i_{\mathrm{o}}^{\prime}\left(1-\theta_{\mathrm{H}}\right) e^{-\mathrm{a} \eta} \\
i_{\mathrm{r}}=F k_{3} \theta_{\mathrm{r}}^{2} \\
i_{\infty}=\frac{k^{\prime \prime} \theta_{\mathrm{H}}}{b} \\
j_{\infty}=\frac{k^{\prime \prime}}{b \sqrt{F k_{3}}} \sqrt{i_{\mathrm{r}}} \\
i_{\mathrm{c}} e^{\mathrm{a} \alpha \eta}=-\frac{b i_{\mathrm{o}}^{\prime}}{k^{\prime \prime}} j_{\infty}+i_{\mathrm{o}}^{\prime}
\end{gathered}
$$

where $i_{\mathrm{r}}=i_{\mathrm{c}}-j_{\infty}$ is the hydrogen recombination current density, $i_{c}$ is the cathodic current density, $b=L / F \mathrm{D}, L$ is the membrane thickness, $F$ is the Faraday constant, $D$ is hydrogen diffusion coefficient, $a=F / R T, \alpha$ is the transfer coefficient, $\eta$ is the overpotential, $R$ is gas constant, $T$ is temperature, $\theta_{\mathrm{H}}$ is the hydrogen surface coverage, $k_{3}$ is the recombination rate constant, $k^{\prime \prime}$ is the thickness dependent adsorption-absorption constant, $i_{\mathrm{o}}^{\prime}=i_{\mathrm{o}} /\left(1-\theta_{\mathrm{e}}\right)$, here $i_{\mathrm{o}}$ is the exchange current density, and $\theta_{\mathrm{e}}$ is equilibrium hydrogen coverage.

Figure 1 shows the cathodic current density, $i_{\mathrm{c}}$, and hydrogen permeation current density, $j_{\infty}$, vs. the cumulative plating time of zinc at $E_{\mathrm{c}}=(1.3 \mathrm{~V} v \mathrm{~s}$. SCE. The figure shows that the cathodic current density decreases more rapidly than the permeation current density as the zinc plate thickness increases. Both $i_{c}$ and $j_{s}$ level off after about $120 \mathrm{~s}$ (approximately $0.09 \mu \mathrm{m}$ zinc thickness).

Figure 2 shows the cathodic current density vs. the applied cell potential, $E_{\mathrm{c}}$, for the bare iron and subsequent zinc layers. The figure shows that the cathodic current density is much lower in the presence of electrodeposited zinc layers than on the bare iron but that there is not a substantial difference in cathodic current between zinc layers

Figure 3 shows the hydrogen permeation current density $v s$. the applied cell potential. The linear regression slopes are shown as straight lines in the figures. The figure shows the permeation rate is significantly lower with zinc

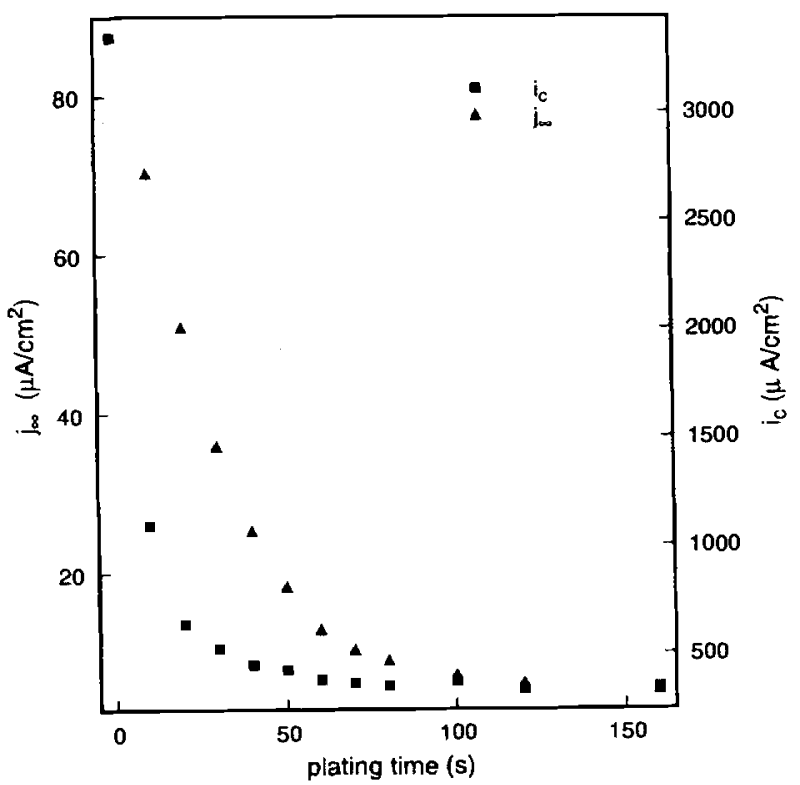

Fig. 1. Cathodic current density, $i_{c}$, and hydrogen permeation current densily, $i_{\infty}, v s$. the cumulative zinc plating time at $E_{c}=-1.3 \mathrm{~V}$ vs. SCE.

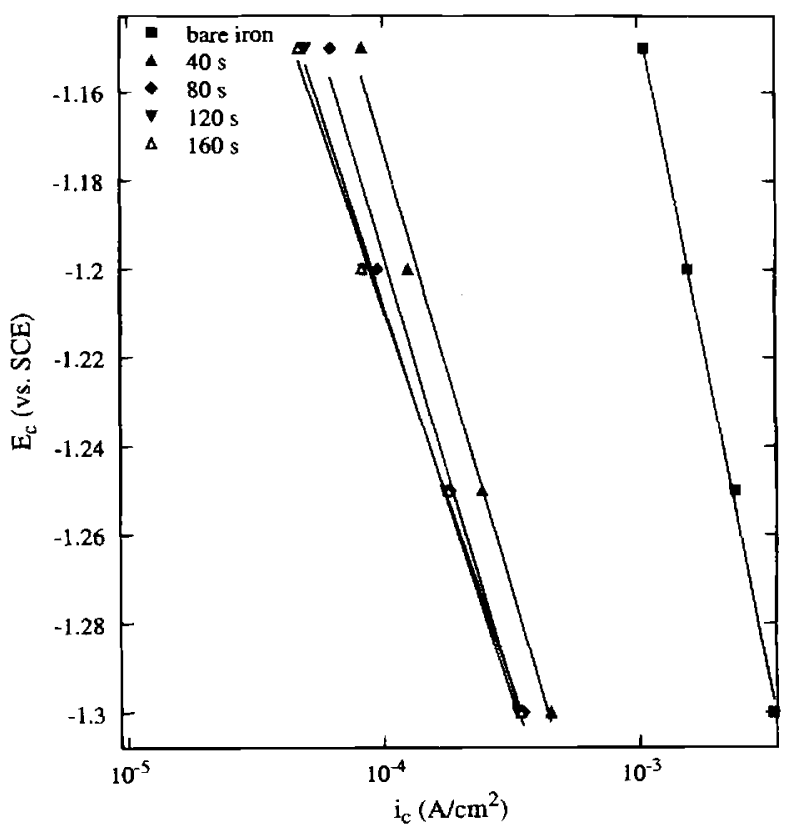

Fig. 2. Cathodic current density, $i_{c r}$ vs. the applied cathodic cell polential, $E_{c}$.

deposited on the surface and decreases with subsequent zinc layers.

The regression slopes from Fig. 2 and 3 are used in Eq. 6 to calculate the transfer coefficient, $\alpha$. Iyer et al. showed that in calculating the transfer coefficient, $\alpha$, it is important to take into effect the fractional hydrogen surface coverage, $\theta_{\mathrm{H}}$. Using the method they described, the following quadratic equation can be found for cases where the $i_{c}$ $v s$. $\eta$ and the $j_{x} v s . \eta$ are linear

$$
\alpha^{2}+\left[\left(2 s-s_{\infty}\right) / a\right] \alpha+\left[s_{c}\left(s_{c}-s_{\infty}\right) / a^{2}\right]=0
$$

where $s_{c}=\partial \ln \left(i_{c}\right) / \partial \eta$ and $s_{x}=\partial \ln \left(j_{x}\right) / \partial \eta$.

Transfer coefficients from the experimental data ranged from 0.4 to 0.7 , and averaged 0.53 for the bare iron and the electrodeposited zinc layers. The method for calculating the transfer coefficient is a quadratic equation ( $\mathrm{Eq} .6$ above) and thus gives two roots. Iyer et al. suggest choos-

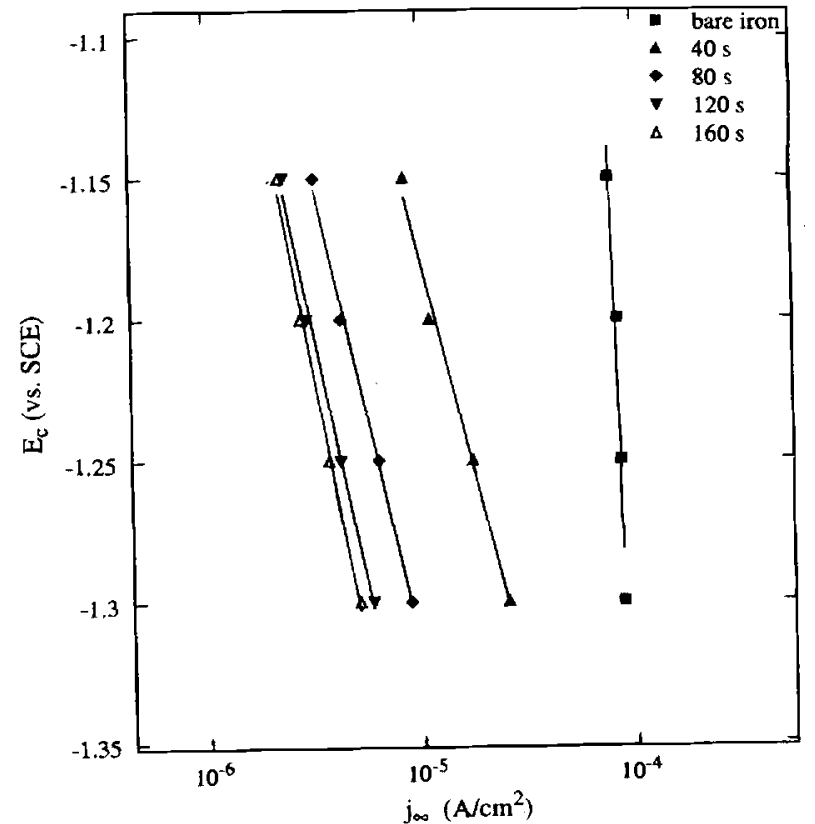

Fig. 3. Steady-state hydrogen permeation current density, $i_{\infty}, v s$. the applied cathodic cell potential, $E_{c}$. 


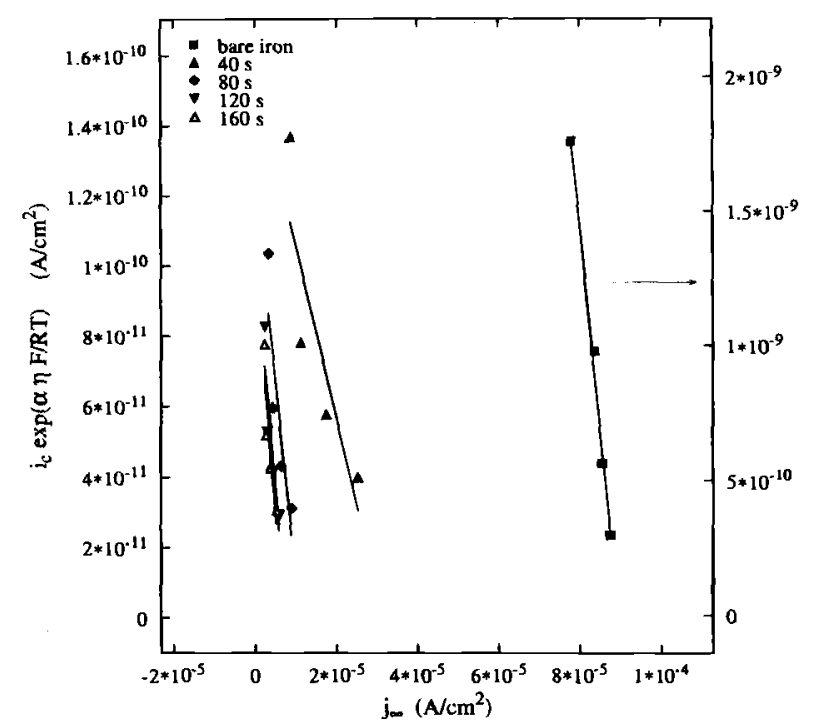

Fig. 4. Steady-stote hydrogen permeation current density, $j_{i \infty}, v s$. the charging function, $i_{c} \exp (\alpha \eta F / R T)$.

ing the root that gives nonnegative values of $i_{\circ}$ and $k^{\prime \prime}$ in later calculations. ${ }^{18}$ In our research, however, both roots for the transfer coefficient $(\alpha)$ give positive values for these constants. Thus there is no nonsubjective way of choosing which $\alpha$ value to use. In addition, since the kinetic mechanism is assumed to be the same in this research (coupled discharge-recombination) and the metal surface is always zinc (except before the very first zinc electroplate), the real transfer coefficient is likely to be the same. Therefore, the value of $\alpha=0.5$ was used in all subsequent calculations in this study.

Figure 4 shows the permeation current density, $j_{\infty}, v s$. the "charging function," $i_{\mathrm{c}} \exp (\alpha \eta F / R T)$ from the left side of Eq. 5 for the bare iron and subsequent zinc layers. Linear regressions of the data appear as lines.

Figures 5 and 6 show the square root of the recombination current density, $\sqrt{i_{r}}$, vs. the permeation current density, $j_{\infty}$, for the bare iron and subsequent zinc layers, respectively. These results show a significant decrease in the

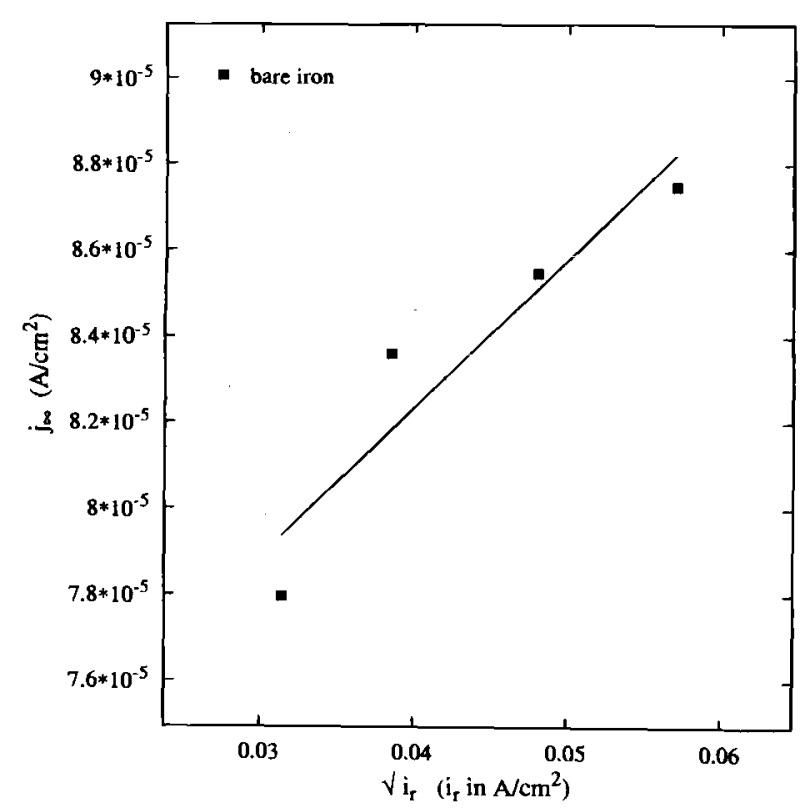

Fig. 5. Square root of the recombination current density, $\sqrt{i_{r}}$, vs. the steady-state hydrogen permeation current density, $j_{\infty,}$ for the bare iron.

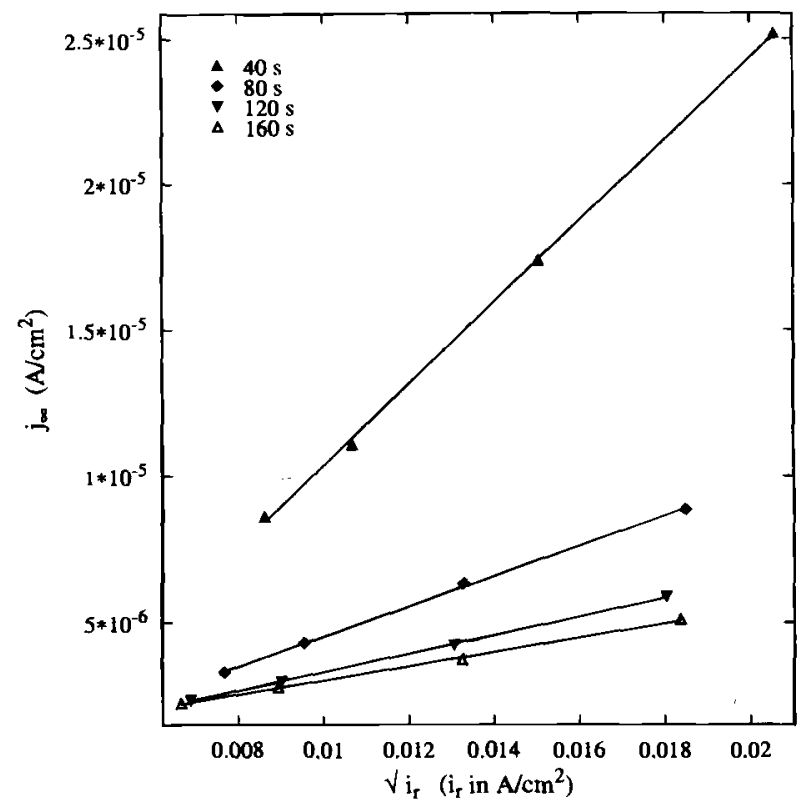

Fig. 6. Square root of the recombination current density, $\sqrt{i_{r}}$, vs. the steady-state hydrogen permeation current density, $j_{\text {os }}$ for the zinc electroplated iron.

permeation current and the recombination current once zinc is plated on the iron. A more gradual decrease in the permeation current relative to the recombination current occurs with successive zinc layers.

Regressions of the experimental data in Fig. 4, 5, and 6 (shown as lines) were used to calculate $k^{\prime \prime}, k_{3}$, and $i_{0}^{\prime}$ via Eq. 4 and 5 . Equation 3 was then used to calculate the corresponding surface coverage, $\theta_{\mathrm{H}}$.

Figure 7 shows the calculated values of the surface coverage, $\theta_{\mathrm{H}}$, for the bare iron using the IPZ model. The points are calculated from the IPZ model results at the experimentally tested overpotentials. The surface coverage of hydrogen decreases from bare iron to the electrodeposited zinc layers, but surface coverage does not change significantly as the zinc coating increases.

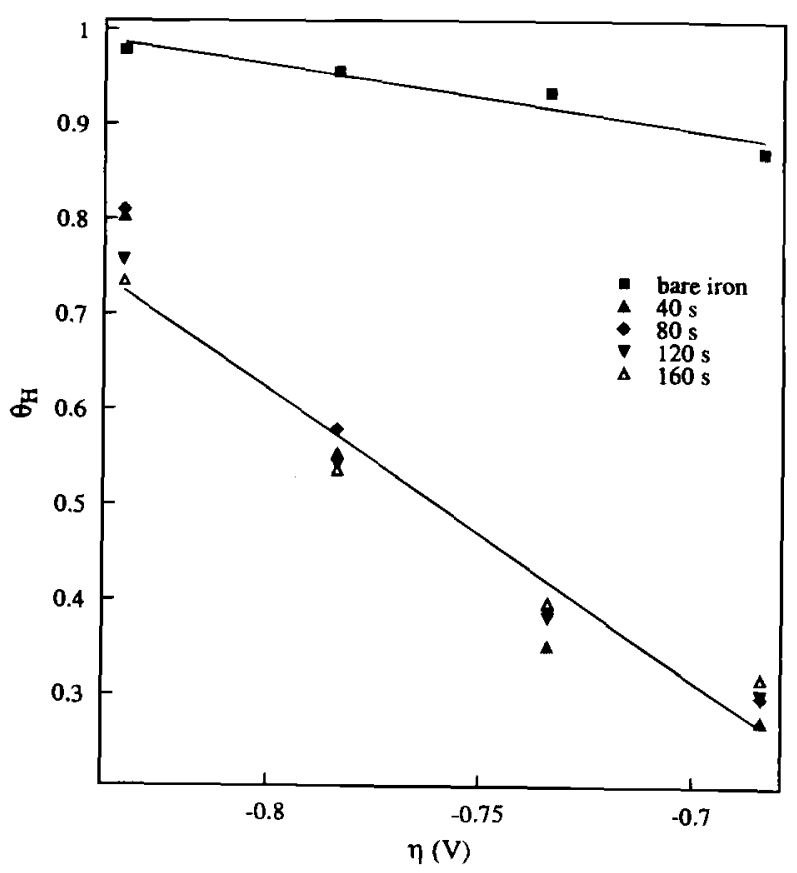

Fig. 7. Overpotential, $\eta$, vs. the hydrogen surface coverage, $\theta_{H}$. 
Table I. IPZ model results.

\begin{tabular}{|c|c|c|c|}
\hline Layer & $i_{0}=i_{0}^{\prime}\left(10^{10} \mathrm{~A} / \mathrm{cm}^{2}\right)$ & $k^{\prime \prime}\left(10^{6} \mathrm{~mol} / \mathrm{cm}^{3}\right)$ & $k_{3}\left(10^{9} \mathrm{~mol} / \mathrm{cm}^{2} \mathrm{~s}\right)$ \\
\hline $\begin{array}{l}\text { Bare iron } \\
\text { (s) }\end{array}$ & 139 & 80.6 & 698 \\
\hline 10 & 6.25 & 72.1 & 10.8 \\
\hline 20 & 1.99 & 62.0 & 9.97 \\
\hline 30 & 1.78 & 41.7 & 7.56 \\
\hline 40 & 1.55 & 28.2 & 5.22 \\
\hline 50 & 1.47 & 20.6 & 5.03 \\
\hline 60 & 1.28 & 14.7 & 4.94 \\
\hline 70 & 1.25 & 11.4 & 4.69 \\
\hline 80 & 1.24 & 9.83 & 4.62 \\
\hline 100 & 1.04 & 8.70 & 8.04 \\
\hline 120 & 1.02 & 6.99 & 6.20 \\
\hline 160 & 1.01 & 6.25 & 8.34 \\
\hline
\end{tabular}

Table II. Average percent decrease in $i_{c}$ and $j_{\text {io }}$ with zinc layers vs. bare iron.

\begin{tabular}{lccccccc}
\hline & $20 \mathrm{~s}$ & $40 \mathrm{~s}$ & $60 \mathrm{~s}$ & $80 \mathrm{~s}$ & $100 \mathrm{~s}$ & $120 \mathrm{~s}$ & $160 \mathrm{~s}$ \\
$i_{\mathrm{c}}(\%)$ & 86 & 90 & 92 & 93 & 92 & 93 & 93 \\
$j_{\infty}(\%)$ & 61 & 82 & 91 & 93 & 95 & 96 & 96
\end{tabular}

The kinetic parameters obtained from the IPZ model calculations on the bare iron and electroplated zinc layers are compared in Table I. The exchange current density, $i_{0}$, and the recombination rate constant, $k_{3}$, decrease rapidly when zinc is first plated, and only a small decrease is seen with successive zinc layers. This decrease in exchange current density accounts for the decrease in the cathodic current density on all of the zinc layers as compared with the bare iron. An associated decrease in the recombination rate constant also occurs when zinc is first plated. The decrease in permeation rate between subsequent zinc covered layers appears to be mostly due to a decrease in the absorption-adsorption constant, $k$, which changes more slowly than the exchange current density.

Table II shows the average percent decrease in the cathodic current density and the permeation current density for several zinc layers as compared to the bare iron. The table shows the same type of response seen in Fig. 1. The hydrogen evolution current decreases rapidly once zinc is plated and does not show rapid change with subsequent layers, however, the permeation current continues to decrease with each zinc layer deposition until approximately $120 \mathrm{~s}$.

\section{Conclusion}

Electroplated thin zinc layers inhibited the HER current and permeation current an average of 93 and $96 \%$, respectively, as compared with bare iron. A very thin layer of zinc caused the HER exchange current density to decrease dramatically but did not decrease the hydrogen permeation rate to the same extent. The hydrogen permeation rate continued to decrease with each zinc layer plated until reaching $96 \%$ inhibition (after $120 \mathrm{~s}$ of plating).

The decrease in the permeation rate of hydrogen through the zinc-covered iron membrane was due to both the decrease in the exchange current density and a decrease in the absorption-adsorption constant.

\section{Acknowledgment}

Technical assistance and financial support by A. John Sedriks, the Office of Naval Research, under Contract No. AAESRT N000014-93-1-1094 are Gratefully acknowledged.
Manuscript submitted Oct. 30, 1995; revised manuscript received Feb. 15, 1996.

The University of South Carolina assisted in meeting the publication cost of this article.

\section{LIST OF SYMBOLS}

a $\quad F / R T$, a constant, $\mathrm{V}^{-1}$

b $\quad L /(F D)$, a constant, $(\mathrm{A} \mathrm{cm})^{-1}$

$E_{\text {oc }}$ open-circuit potential, V

$E_{\mathrm{c}} \quad$ cathodic potential, V

$F \quad$ Faraday constant, $96,487 \mathrm{C} / \mathrm{eq}$

$i$ current density, $\mathrm{A} / \mathrm{cm}^{2}$

$i_{\text {c }} \quad$ cathodic current density, $\mathrm{A} / \mathrm{cm}^{2}$

$i_{\mathrm{r}}$ hydrogen recombination current density, $\mathrm{A} / \mathrm{cm}^{2}$

$i_{\text {a }}$ exchange current density, $\mathrm{A} / \mathrm{cm}^{2}$

$i_{\mathrm{o}}^{\prime} \quad i_{\mathrm{o}} /\left(1-\theta_{\mathrm{e}}\right), \mathrm{A} / \mathrm{cm}^{2}$

$j_{x}$ steady-state hydrogen permeation current density, $\mathrm{A} / \mathrm{cm}^{2}$

$k_{3} \quad$ recombination rate constant, $\mathrm{mol}\left(\mathrm{cm}^{2} \mathrm{~s}\right)^{-1}$

$k^{\prime \prime} \quad$ thickness dependent absorption-adsorption constant, $\mathrm{mol} \mathrm{cm} \mathrm{cm}^{-3}$

$L \quad$ membrane thickness, $\mathrm{cm}$

$R$ gas constant, $8.3143 \mathrm{~J}(\mathrm{~mol} \mathrm{~K})^{-1}$

$T$ temperature, $\mathrm{K}$

Greek

$\alpha \quad$ transfer coefficient, dimensionless

$\theta_{\mathrm{e}}$ equilibrium hydrogen surface coverage, dimensionless

$\theta_{\mathrm{H}} \quad$ hydrogen surface coverage, dimensionless

$\eta \quad$ overpotential, $\mathrm{V}$

\section{REFERENCES}

1. M. A. V. Devanathan and Z. Stachurski, Proc. $R$. Soc. London, Ser. A, 270, 90 (1962).

2. M. A. V. Devanathan and Z. Stachurski, This Journal, $110,886(1963)$.

3. M. A. V. Devanathan and Z. Stachurski, ibid., 111, 619 (1964).

4. R. A. Oriani, Ann. Rev. Mater. Sci., 8, 327 (1978).

5. J. O'M. Bockris and A. K. N. Reddy, Modern Electrochemistry, Vol. 2, p. 1231, Plenum Press, New York (1970).

6. J. O'M. Bockris and P. K. Subramanyan, Electrochim. Acta, 16, 2169 (1971).

7. R.-H. Song and S. Pyun, This Journal, 137, 1051 (1990).

8. J.-M. Chen and J.-K. Wu, Plating Surf. Finish., 10, 74 (1992).

9. J.-M. Chen and J.-K. Wu, Corros. Sci., 33, 657 (1992).

10. M. Zamanzadeh, A. Allam, C. Kato, B. Ateya, and H. W. Pickering, This Journal, 129, 284 (1982).

11. B. N. Popov, G. Zheng, and R. E. White, Corrosion, 50, 613 (1994).

12. B. N. Popov, G. Zheng, and R. E. White, ibid., 51, 429 (1995).

13. G. Zheng, B. N. Popov, and R. E. White, This Journal, 140, 3153 (1993).

14. G. Zheng, B. N. Popov, and R. E. White, ibid., 141, 1220 (1994).

15. G. Zheng, B. N. Popov, and R. E. White, ibid., 141, 1526 (1994).

16. B. N. Popov, G. Zheng, and R. E. White, Corros. Sci., 36, 2139 (1994)

17. G. Zheng, B. N. Popov, and R. E. White, J. Appl. Electrochem., 25, 212 (1995).

18. R. N. Iyer, H. W. Pickering, and M. Zamanzadeh, This Journal, 136, 2463 (1989).

19. R. N. Iyer and H. W. Pickering, Ann. Rev. Mater. Sci., 20, 299 (1990). 